\title{
Gastrointestinal Manifestations of Systemic Diseases in Critically Ill
}

\author{
Alok K Panigrahy ${ }^{1}$, Shrikanth Srinivasan ${ }^{2}$
}

\begin{abstract}
Systemic disorders can have gastrointestinal (Gl) manifestations which are characterized by nausea, vomiting, diarrhea, constipation, abdominal pain, jaundice, and abnormal liver function tests. These gastrointestinal symptoms can be signs of various immunologic, infectious, and endocrine diseases. Gastrointestinal manifestations can be the first signs and symptoms for which the patient can be admitted in a critical care unit. In this article, we will discuss the GI manifestations of various topical diseases, endocrine diseases, and immunological diseases which are the major bulk of patients in intensive care unit (ICU).

Keywords: Acute liver failure, Acute pancreatitis, COVID-19, Dengue.

Indian Journal of Critical Care Medicine (2020): 10.5005/jp-journals-10071-23610
\end{abstract}

\section{Gastrointestinal Manifestations of Tropical Diseases \\ Malaria}

Gastrointestinal (GI) manifestations are common in malaria. Gastrointestinal manifestations are more common in pediatric patient than adults. These include dyspepsia, vomiting, diarrhea, hepatitis, gastrointestinal bleed, abdominal pain, subacute intestinal obstruction such as presentation and acute abdomen. There are few case reports of perforated duodenal ulcer. ${ }^{1}$

Mild jaundice is common in malaria. Sometimes severe jaundice may occur in $P$. falciparum infection due to hemolysis, hepatocyte injury, and cholestasis. Liver manifestations are more common in adults than children. Hypoglycemia is a common complication of severe malaria. It occurs due to diminished hepatic gluconeogenesis, depletion of liver glycogen stores, increase in the consumption of glucose by the host (and, to a much less extent, the parasite), and quinine-induced hyperinsulinemia. Hypoglycemia is more common in children and pregnant women.

\section{Leptospirosis}

Leptospirosis may present with wide variety of Gl and non-Gl complications. GI manifestations are nausea, vomiting, abdominal pain, acalculous cholecystitis, ${ }^{2}$ enteritis, pancreatitis, ${ }^{3}$ peritonitis, and liver failure. Liver failure in leptospirosis is characterized by increased bilirubin level with normal level of aminotransferases. ${ }^{4}$

\section{Enteric Fever}

Various GI manifestations of eneteric fever are loss of appetite and weight loss, coated tongue, abdominal pain, pea soup diarrhea, and marked constipation. Dreadest GI complications are inrestinal hemorrhage and perforation. Terminal ileum is most commonly affected followed by the ileocecal valve, the ascending colon, and the transverse colon. Left side colon is least affected. In colonoscopy, multiple variable-sized punched out ulcers with elevated margin are found. Intestinal perforation generally occurs more frequently among adults than children and is associated with high mortality rates. ${ }^{5}$ Typhoid intestinal perforation usually occurs during the third

\footnotetext{
1,2Department of Critical Care Medicine, Manipal Hospital, Dwarka, Delhi, India

Corresponding Author: Shrikanth Srinivasan, Department of Critical Care Medicine, Manipal Hospital, Dwarka, Delhi, India, Phone: +910124-4030723, e-mail: srinivasan.shrikanth@gmail.com

How to cite this article: Panigrahy AK, Srinivasan S. Gastrointestinal Manifestations of Systemic Diseases in Critically III. Indian J Crit Care Med 2020;24(Suppl 4):S190-S192.

Source of support: Nil

Conflict of interest: None
}

week of febrile illness and is due to necrosis of the Peyer's patches in the antimesenteric bowel wall. ${ }^{6}$

\section{Dengue}

Gastrointestinal symptoms are common in dengue patient. More than half of patients presented with nausea, vomiting, and abdominal pain. Some patients also presented with diarrhea. Few patients also develop gastrointestinal bleed. Hepatomegaly found around $18 \%$ of patients. Abnormal LFT is characterized by transaminitis in around $90 \%$ of cases. However, transaminitis is mild to moderate. Few patients develop fulminant liver failure due to hepatitis or focal necrosis of liver causing hepatic encephalopathy and death.

\section{Gastrointestinal Manifestations of COVID-19}

Unexpected pneumonia-like symptoms was found in Wuhan, China, in December 2019. Subsequently, it was labeled as SARS CoV-2 which resulted widespread pandemic. Incubation period ranged from 2 to 11 days. ${ }^{7}$ Usual symptoms are fever, cough, headache, and shortness of breath. Some atypical symptoms are anosmia and loss of taste. Many patients presented gastrointestinal manifestations like nausea, vomiting, abdominal pain, and diarrhea. Some studies have also found the presence of COVID-19 viruses in

() The Author(s). 2020 Open Access This article is distributed under the terms of the Creative Commons Attribution 4.0 International License (https://creativecommons. org/licenses/by-nc/4.0/), which permits unrestricted use, distribution, and non-commercial reproduction in any medium, provided you give appropriate credit to the original author(s) and the source, provide a link to the Creative Commons license, and indicate if changes were made. The Creative Commons Public Domain Dedication waiver (http://creativecommons.org/publicdomain/zero/1.0/) applies to the data made available in this article, unless otherwise stated. 
anorectal swabs and in stool samples, despite negative in upper respiratory tract samples. ${ }^{8}$ Different studies demonstrated the presence of angiotensin-converting enzyme 2 receptor (ACE2) in gastrointestinal epithelial cells which might facilitate the evidence of this possible route for COVID-19 infection. ${ }^{9}$ ACE 2 receptors are expressed in glandular cells of gastric, duodenal, and rectal epithelial supporting entry of COVID-19 into host cells.

Up to $60 \%$ patients develop liver impairment characterized by transaminitis, elevated bilirubin, low serum albumin, and elevated alkaline. $^{10}$

\section{Gastrointestinal Manifestations of Endocrine Disease}

\section{Gastrointestinal Manifestations in Diabetic Ketoacidosis}

In all, 50-75\% of patients with diabetic ketoacidosis (DKA) presented with gastrointestinal symptoms such as nausea, vomiting, abdominal pain, and abdominal distention. ${ }^{11}$ The mechanism of gastrointestinal symptoms is due to central neurogenic response the ketoacidosis, gastric atony, generalized ileus, increased level of counter regulatory hormones such as glucagon and catecholamines, gastritis, or pancreatitis. These symptoms resolve with fluid therapy and insulin. ${ }^{12}$

Combination of clinical history, physical examination, and laboratory examination is required for differential diagnosis of DKA from cholecystitis, acute pancreatitis, and mesenteric vascular insufficiency. Nausea, vomiting, and abdominal pain associated with DKA are acute in onset in contrast to intermittent abdominal pain over days to weeks in intra-abdominal disorder. On physical examination, there is generalized abdominal pain in DKA in contrast to localized abdominal pain in intra-abdominal disorder.

Laboratory evaluation in DKA is required to differentiate it from atypical presentation of myocardial infraction, intestinal perforation, gastric atony, generalized ileus, and obstruction. These include ECG, CBC, abdominal films, serum enzymes such as serum amylase, lipase, alkaline phosphatase, SGOT, SGPT, CPK, glucose, electrolytes, urea, and creatinine. In DKA, there is increase in leukocyte count with toxic granulation because of increase in stress hormone. Hematocrit also increases because of severe dehydration. Forty to $79 \%$ of DKA patients have increased serum amylase levels. ${ }^{13}$ In the absence of any symptoms, the level of serum amylase can be increased to more than three times of normal value. But the serum level of lipase is normal or slightly increased.

There is derangement in SGOT, SGPT, LDH, and other enzymes in DKA. In an observational study, Knight et al. found that $33 \%$ of patients had mild to marked elevations in hepatic enzymes. ${ }^{13}$ Abdominal pain, nausea, vomiting occurring secondary to acidosis resolve within 12-24 hours. If the pain persist for more than 12-24 hours additional etiology should be sought.

\section{Gastrointestinal Manifestations in ThYROID Disorder}

In all, $30-50 \%$ of hyperthyroid patients have gastrointestinal symptoms. ${ }^{14}$ Gastrointestinal symptoms range from frequent bowel movements, diarrhea, chronic dyspeptic symptoms such as epigastric pain and fullness, nausea, and vomiting. Sometimes intractable vomiting is also reported in hyperthyroidism. There is gastrointestinal motor dysfunction manifested as altered intestinal motility and decreased intestinal transit time in hyperthyroidism. The mechanism behind gastrointestinal manifestations is not clear, but one of the proposed hypotheses is due to direct effect of hormone on central nervous system.

Dysphagia is a rare manifestation of hyperthyroidism which is due to direct compression of thyroid on esophagus and myopathy of striated muscles of pharynx and esophagus. Dysphagia resolves on correction of hyperthyroidism. ${ }^{15}$

In $27-37 \%$ of patients, there is increase in SGOT and SGPT. ${ }^{16}$ In $64 \%$ of patients, there is increase in alkaline phosphatase because of high turnover in bones. ${ }^{17}$ Sometimes, there is mild increase in gamma glutamyl transferase and bilirubin levels. Few case reports of fulminant hepatic failure have been described in hyperthyroidism. Long-term untreated hyperthyroidism can lead to cirrhosis.

Graves' disease patients are at increased risk of coeliac disease and ulcerative colitis. Some case reports of primary biliary cirrhosis reported in graves' disease.

Severe hypothyroidism may lead to disturbance in esophageal peristalsis. There is reduced velocity and amplitude of esophageal peristalsis and decrease in lower esophageal sphincter pressure which all contribute to dysphagia. Other gastrointestinal manifestations are decreased appetite, but there is weight gain because of decreased metabolism and water retention. There is reduction in peristalsis and constipation. Although rare in severe hypothyroidism, there may be severe ileus and pseudo-obstruction. Sometimes, there is diarrhea in severe hypothyroidism due to bacterial overgrowth syndrome. Severe upper gastrointestinal bleeding refractory to usual treatment also reported in severe hypothyroidism.

Mechanism for gastrointestinal dysfunctions are multifactorial with possible explanations being alternation in hormone receptors, neuromuscular disorder, and myopathy. Thyroid hormone deficiency may influence transepithelial flux by inhibiting $\mathrm{Cl}^{-}$/ $\mathrm{HCO}_{3}{ }^{-}$anion exchange which have effect on intestinal motility. ${ }^{18}$

In $50 \%$ of patients with hypothyroidism, there is some degree of mild liver abnormality, despite normal histological findings. ${ }^{19}$ Myxoedema ascites is found in some long-standing case of hypothyroidism which is characterized by serum to ascites albumin gradient more than $1.1 \mathrm{~g} / \mathrm{dL}$ with high protein content. ${ }^{20}$ Hypothyroidism patients are also at high risk of Crohn's disease, pernicious anemia, and primary biliary cirrhosis.

\section{Gastrointestinal Manifestations in Autoimmune Disorders \\ Inflamatory Bowel Diseases}

Ulcerative colitis and Crohn disease are autoimmune diseases together called as inflammatory bowel disease. They are characterized by widespread intestinal inflammation and ulceration. They are admitted to intensive care unit (ICU) with presentation like lower gastrointestinal bleeding, intestinal perforation leading to severe abdominal sepsis, and septic shock. ${ }^{21}$

\section{Antiphospholipid Syndrome}

Antiphospholipid syndrome (APS) may be associated with systemic lupus erythematosus or as an isolated finding. Since gastrointestinal tract is highly vascular and rich in capillary, it is highly vulnerable to be affected by autoimmune disease. There is widespread vascular thrombosis in antiphospholipid syndrome due to procoagulant effect of autoantibodies. Catastrophic antiphospholipid syndrome 
may manifest as ischemia involving esophagus, stomach, small intestine, and colon resulting in gastrointestinal bleeding, abdominal pain, and esophageal necrosis with perforation. ${ }^{22}$ Thrombosis of hepatic and portal vein may result Budd-Chiari syndrome, hepatic veno-occlusive disease, hepatic infraction, portal hypertension, and cirrhosis. ${ }^{23}$

\section{Systemic Lupus Erythematosus}

Up to $40 \%$ of patients with systemic lupus erythematosus (SLE) have gastrointestinal manifestations. ${ }^{24}$ These manifestations may be due to vasculitis or due to side effect of medications used for treatment. Dysphagia is the most common gastrointestinal manifestation which may be due to gastrointestinal motility disorder, gastroesophageal reflux disease, or due to infection by candida, CMV, and herpes simplex virus. Some case repots of intestinal pseudo-obstruction reported in SLE which is characterized by abdominal pain, distention, and bloating. ${ }^{25}$ Mechanism behind pseudo-obstruction is unknown, but possible explanations are due to immune complex deposition in smooth muscles of intestine and due to vasculitis induced chronic ischemia. ${ }^{26}$

Other gastrointestinal manifestations are protein losing enteropathy, autoimmune hepatitis, lupus hepatitis, acute pancreatitis, mesenteric vessel vasculitis, and peritonitis which may lead to admission in ICU. ${ }^{27}$

\section{References}

1. BhandariTR, ShahiS, Poudel R, Chaudhary N. A child with severe malaria presenting with acute surgical abdomen (duodenal perforation). Case Rep Pediatr 2016;2016:3092130. DOI: 10.1155/2016/3092130.

2. Vilaichone RK, Mahachai V, Wilde H. Acute acalculous cholecystitis in leptospirosis. J Clin Gastroenterol 1999;29(3):280-283. DOI: 10.1097/00004836-199910000-00012.

3. Kaya E, Dervisoglu A, Eroglu C, Polat C, Sunbul M, Ozkan K. Acute pancreatitis caused by leptospirosis: report of two cases. World J Gastroenterol 2005;11(28):4447-4449. DOI: 10.3748/wjg.v11.i28. 4447.

4. Wysocki J, Liu Y, Shores N. Leptospirosis with acute liver injury. Proc (Bayl Univ Med Cent) 2014;27(3):257-258. DOI: 10.1080/08998280.2014.11929130.

5. Gupta SP, Gupta MS, Bhardwaj S, Chugh TD. Current clinical patterns of typhoid fever: a prospective study. J Trop Med Hyg 1985;88(6): 377-381.

6. Bitar R, Tarpley J. Intestinal perforation in typhoid fever: a historical and state-of-the-art review. Rev Infect Dis 1985;7(2):257-271. DOI: 10.1093/clinids/7.2.257.

7. Backer JA, Klinkenberg D, Wallinga J. Incubation period of 2019 novel coronavirus(2019-nCoV) infections among travellers from Wuhan, China, 20-28 January 2020.

8. Xu Y, Li X, Zhu B, Liang H, Fang C, Gong Y, et al. Characteristics of pediatric SARS-CoV-2 infection and potential evidence for persistent fecal viral shedding. Nat Med 2020;26(4):502-505. DOI: 10.1038/ s41591-020-0817-4.

9. Xiao F, Tang M, Zheng X, Liu Y, Li X, Shan H,. Evidence for gastrointestinal infection of SARS-CoV-2. Gastroenterology 2020;158(6):1831-1833.e3. DOI: 10.1053/j.gastro.2020.02.055.

10. Chau TN, Lee KC, Yao H, Tsang TY, Chow TC, Yeung YC, et al. SARSassociated viral hepatitis caused by a novel coronavirus: report of three cases. Hepatology 2020;39(2):302-310. DOI: 10.1002/ hep.20111?.

11. Marble A, White P, Bradley RF, Joslin's Diabetes Mellitus. 11th ed., Philadelphia: Lea and Febiger; 1971.

12. Campbell IW, Duncan LJP, Innes JA, MacCuish AC, Munro JF. Abdominal pain in diabetic metabolic decompensation: clinical significance. JAMA 1975;233(2):166-168. DOI: 10.1001/jama.1975.03260020052026.

13. Knight AH, Williams DN, Ellis G, Goldberg DM. Significance of hyperamylasaemia and abdominal pain in diabetic ketoacidosis. Br Med J 1973;3(5872):128-131. DOI: 10.1136/bmj.3.5872.128.

14. Maser C, Toset A, Roman S. Gastrointestinal manifestations of endocrine disease. World J Gastroenterol 2006;12(20):3174-3179. DOI: 10.3748/wjg.v12.i20.3174.

15. Chiu WY, Yang CC, Huang IC, Huang TS. Dysphagia as manifestation of thyrotoxicosis: report of three cases and literature review. Dysphagia 2004;19(2):120-124. DOI: 10.1007/s00455-003-0510-z.

16. Thompson Jr P, Strum D, Boehm T, Wartofsky L. Abnormalities of liver function tests in tyrotoxicosis. Mil Med 1978;143(8):548-551. DOI: 10.1093/milmed/143.8.548.

17. Biscoveanu M, Hasinski S. Abnormal results of liver function tests in patients with graves' disease. Endocr Pract 2000;6(5):367-369. DOI: 10.4158/EP.6.5.367.

18. Tenore A, Fasano A, Gasparini N, Sandomenico ML, Ferrara A, Di Carlo $A$, et al. Thyroxine effect on intestinal $\mathrm{Cl}-/ \mathrm{HCO}_{3}$ - exchange in hypo- and hyperthyroid rats. J Endocrinol 1996;151(3):431-437. DOI: 10.1677/joe.0.1510431.

19. Kim D, Ryan J. Gastrointestinal manifestations of systemic diseases Feldman M, Friedman L, Sleisenger M, ed. Gastrointestinal and Liver Disease: Pathophysiology/Diagnosis/Management. 7th ed., Philadelphia: Saunders; 2002.

20. Ji JS, Chae HS, Cho YS, Kim HK, Kim SS, Kim CW, et al. Myxedema ascites: case report and literature review. J Korean Med Sci 2006;21(4):761-764. DOI: 10.3346/jkms.2006.21.4.761.

21. Malhotra A, Mandip KC, Shaukat A, Rector T. All-cause hospitalizations for inflammatory bowel diseases: can the reason for admission provide information on inpatient resource use? A study from a large veteran affairs hospital. Mil Med Res 2016;3(1):28. DOI: 10.1186/ s40779-016-0098-x.

22. Dempsey AC. Autoimmune diseases and their effect on the Gl tract. SGNA's 37th annual course, april 30-may 5, 2010, Orlando, Florida. Gastroenterol Nurs 2010;33(2):151.

23. Uthman I, Khamashta M. The abdominal manifestations of the antiphospholipid syndrome. Rheumatology (Oxford) 2007;46(11):1641-1647. DOI: 10.1093/rheumatology/kem158.

24. Hoffman BI, Katz WA. The gastrointestinal manifestations of systemic lupus erythematosus: a review of the literature. Semin Arthritis Rheum 1980;9(4):237-247. DOI: 10.1016/0049-0172(80) 90016-5.

25. Ceccato F, Salas A, Góngora V, Ruta S, Roverano S, Marcos JC, et al. Chronic intestinal pseudo-obstruction in patients with systemic lupus erythematosus: report of four cases. Clin Rheumatol 2008;27(3):399. DOI: 10.1007/s10067-007-0760-5.

26. Mok MY, Wong RW, Lau CS. Intestinal pseudo-obstruction in systemic lupus erythematosus: an uncommon but important clinical manifestation. Lupus 2000;9(1):11-18. DOI: $10.1177 / 096120330000900104$.

27. Cervera R, Espinosa G, Cordero A, Oltra MR, Unzurrunzaga A, Rossiñol $T$, et al. Intestinal involvement secondary to the antiphospholipid syndrome (APS): clinical and immunologic characteristics of 97 patients: comparison of classic and catastrophic APS. Semin Arthritis Rheum 2007;36(5):287. DOI: 10.1016/j.semarthrit.2006.09.003. 